\title{
Definition of quotations in speech
}

\author{
MARIANNE RATHJE
}

Quotations and quotatives have been examined extensively by sociolinguists in recent years. However, quotations in speech are usually not clearly defined. In this article I propose a definition of quotations in speech. In my efforts to do so, I will move away from merely equating quotations with direct speech, and question the idea of repetition, which is often connected with quotations. Additionally, I will relativize the idea of repetition by comparing it to the notion of construction. Finally, the traditional view regarding who is responsible for the quotation will be modified. The need to define quotations arises from the desire to be able to decide, in quantitative studies, what counts as a quotation and what does not. But as this article will reflect, the work on the definition of quotations has also become a more thorough characterization of the nature of the quotation itself. This article can therefore be seen as an overview of how quotations have been understood in sociolinguistics. 